\title{
SISTEM INFORMASI PENILAIAN SISWA PADA SMK MAARIF KABUPATEN TEGAL
}

\author{
Arif Rakhman ${ }^{1}$, Ahmad Maulana ${ }^{2}$ \\ Program Studi D3 Teknik Komputer \\ Politeknik Harapan Bersama Tegal \\ Cakrakirana7@gmail.com ${ }^{1}$, maulanaahmad@gmail.com²
}

\begin{abstract}
Received: April 26, 2021. Revised: May 05, 2021. Accepted: May 22, 2021. Published: June 20, 2021. Issue Period: Vol.5 No.1 (2021), Pp.26-34
\end{abstract}

\begin{abstract}
Abstrak: Perkembangan ilmu pengetahuan dan teknologi sudah makin cepat, salah satunya adalah di bidang komputer. Saat ini komputer memegang peranan penting dalam mempermudah penyelesaian suatu pekerjaan, meningkatkan efisiensi kerja serta meningkatkan kreatifitas dan aktivitas. SMK Maarif Kabupaten Tegal adalah salah satu organisasi pendidikan dan memerlukan penyediaan layanan informasi pengolahan data yang cepat, tepat dan akurat guna mendukung pelayanan penyediaan informasi kepada siswa dan masyarakat. Tujuan penulisan Tugas Akhir ini untuk mempelajari, menganalisis, merancang dan mengimplementasikan Sistem Informasi Penilaian Siswa pada SMK Maarif Kabupaten Tegal dengan menggunakan PHP dan Mysql. Tahap awal pada penelitian ini adalah pencarian ide pembuatan sistem informasi penilaian ini serta mengumpulkan data - data yang akan di olah dan dibutuhkan dalam sistem informasi penilain dengan metode observasi pada SMK Maarif Kabupaten Tegal. Hasil akhir dari penelitian ini adalah sistem informasi penilaian berbasis Web yang dapat memberikan informasi hasil akhir semester siswa SMK Maarif Kabupaten Tegal.
\end{abstract}

Kata kunci: Website, Sistem Informasi Penilaian, Hasil Nilai Akhir Semester.

\begin{abstract}
The development of science and technology has accelerated, one of which is in the field of computers. Computers play an essential role in completing work completion, increasing work efficiency and increasing creativity and activity. SMK Maarif, Tegal Regency is an educational organization and requires fast, precise and accurate data processing services to support the provision of information to students and the public. The purpose of this final project is to study, analyze, design and implement a Student Assessment Information System at SMK Maarif, Tegal Regency using PHP and Mysql. The initial stage of this research is the search for making this cost information system and collecting data that will be carried out and needed in the assessment information system using the observation method at SMK Maarif, Tegal Regency. The final result of this research is a web-based information system that can provide information on the last semester results of SMK Maarif, Tegal Regency students.
\end{abstract}

Keywords: Website, Assessment Information System, Semester Final Score Results.

DOI: $10.52362 /$ jisicom.v5i1.452

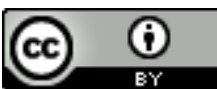

Ciptaan disebarluaskan di bawah Lisensi Creative Commons Atribusi 4.0 Internasional. 
Journal of Information System, Informatics and Computing

Website/URL: http://journal.stmikjayakarta.ac.id/index.php/iisicom

Email: jisicom@stmikjayakarta.ac.id , jisicom2017@gmail.com

\section{PENDAHULUAN}

Perkembangan ilmu pengetahuan dan teknologi sudah makin cepat, salah satunya adalah di bidang komputer. Saat ini komputer memegang peranan penting dalam mempermudah penyelesaian suatu pekerjaan, meningkatkan efisiensi kerja serta meningkatkan kreatifitas dan aktivitas. Hal ini dibuktikan dengan banyaknya perusahaan atau instansi pemerintahan yang menggunakan sistem komputerisasi sebagai alat bantu untuk mempermudah pekerjaan dan menjadikan perusahaan atau instansi pemerintah memiliki mutu yang tinggi.

Sekolah adalah salah satu organisasi pendidikan dalam memberikan pelayanan kepada masyarakat dalam bidang pendidikan. Salah satu unsur terpenting dari suatu sekolah adalah siswa dan nilai dari siswa tersebut. Tidak jarang data nilai siswa yang dicatat dan disimpan secara manual, akan memakan waktu dalam pengerjaannya. Dengan mengunakan komputer, waktu pengerjaan dapat dihemat dan dalam penyimpanan data lebih aman bila dibandingkan dengan penyimpanan data dalam bentuk kertas atau arsip, serta dapat mengurangi faktor kesalahan manusia (human error). Oleh karena itu perlu penggunaan komputer sebagai alat bantu untuk pengolahan data nilai siswa dengan menggunakan aplikasi yang dirancang sedemikian rupa sesuai dengan kebutuhan sekolah[1].

SMK Maarif Kabupaten Tegal yang beralamat di jalan Raya Selatan Margasari No 1 kabupaten Tegal dengan jumlah siswa sekitar 980 dari 30 kelas dan 4 jurusan memerlukan penyediaan layanan informasi pengolahan data yang cepat, tepat dan akurat guna mendukung pelayanan penyediaan infrmasi kepada siswa dan masyarakat.

Sistem informasi penilaian siswa yang terdapat di SMK Maarif Kabupaten Tegal masih menggunakan pengolahan data nilai secara manual dengan cara menulis menggunakan alat tulis pada lembar penilaian rapot, dan proses pengolahan data nilai disimpan secara terbuka pada rak lemari, sehingga penyediaan informasi penilaian akan tidak efektif dan tidak efesien karena waktu tersita cukup banyak dan resiko yang ditanggung cukup besar apabila data hilang atau rusak. Dengan proses pengolahan nilai yang terkomputerisasi akan memudahkan pengerjaan baik waktu dan dalam penyimpanan data lebih aman, serta kesalahan pekerjaan dapat mudah teratasi. Sistem informasi dengan berbasis Web Application agar dapat diakses menggunakan penjelajah web melalui suatu jaringan seperti internet dan intranet, sehingga pengguna dapat melakukan proses kerja diluar kantor atau dimana saja yang tersedia jaringan internet.

\section{METODE DAN MATERI}

\subsection{Rencana Penelitian}

Pada tahap ini akan melaksakan proses pengumpulan data, menganalisa, mengimplementasikan dan pembuatan projek sistem informasi yang nanti akan dipresentasikan.

\subsection{Analisis Penelitian}

Pada tahap ini melakukan identifikasi terhadap sekolah SMK Maarif Kabupaten Tegal, dari hasil tersebut diketahui bahwa proses pengolahan nilai siswa masih dicatat dan disimpan secara manual.

\subsection{Implementasi}

Pada tahap ini akan dilakukan pengimplementasian untuk penyelesaian pekerjaan dengan menggunakan alat atau sarana penelitian yang berlaku untuk memperoleh hasil.

1. Bahan Penelitian

Bahan yang digunakan dalam penelitian ini adalah:
a) Data siswa
b) Data Guru
c) Data Jurusan

DOI: $10.52362 /$ jisicom.v5i1.452

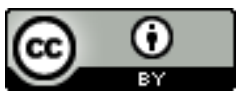

Ciptaan disebarluaskan di bawah Lisensi Creative Commons Atribusi 4.0 Internasional. 
e-ISSN : 2597-3673 (Online), p-ISSN : 2579-5201 (Printed)

Vol.5 No.1, Juni 2021

Journal of Information System, Informatics and Computing

Website/URL: http://journal.stmikjayakarta.ac.id/index.php/iisicom

Email: jisicom@stmikjayakarta.ac.id , jisicom2017@gmail.com
d) Data Kelas
e) Data Mata Pelajaran
f) Data Nilai

2. Prosedur Penelitian

Jenis data yang digunakan adalah Data primer dimana data yang diperoleh langsung dari sumbernya.

3. Activity Diagram

1. Data Guru

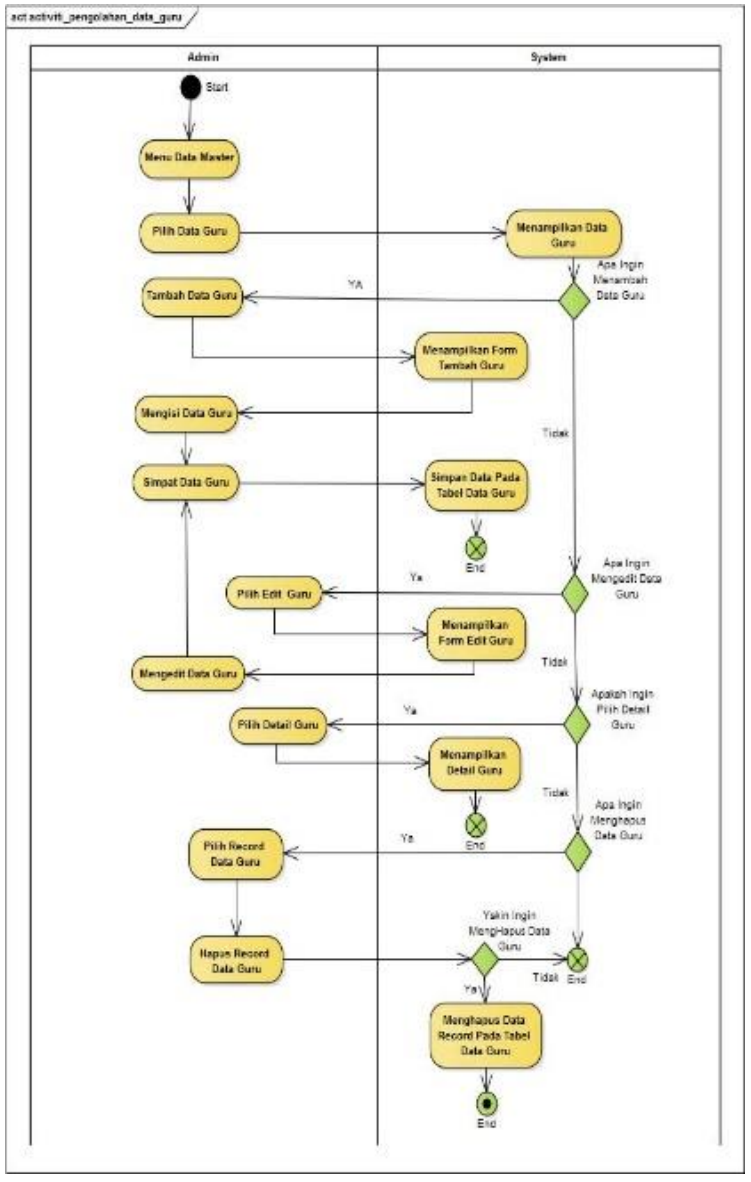

Gambar 1. Activity Data Guru
2. Data Siswa

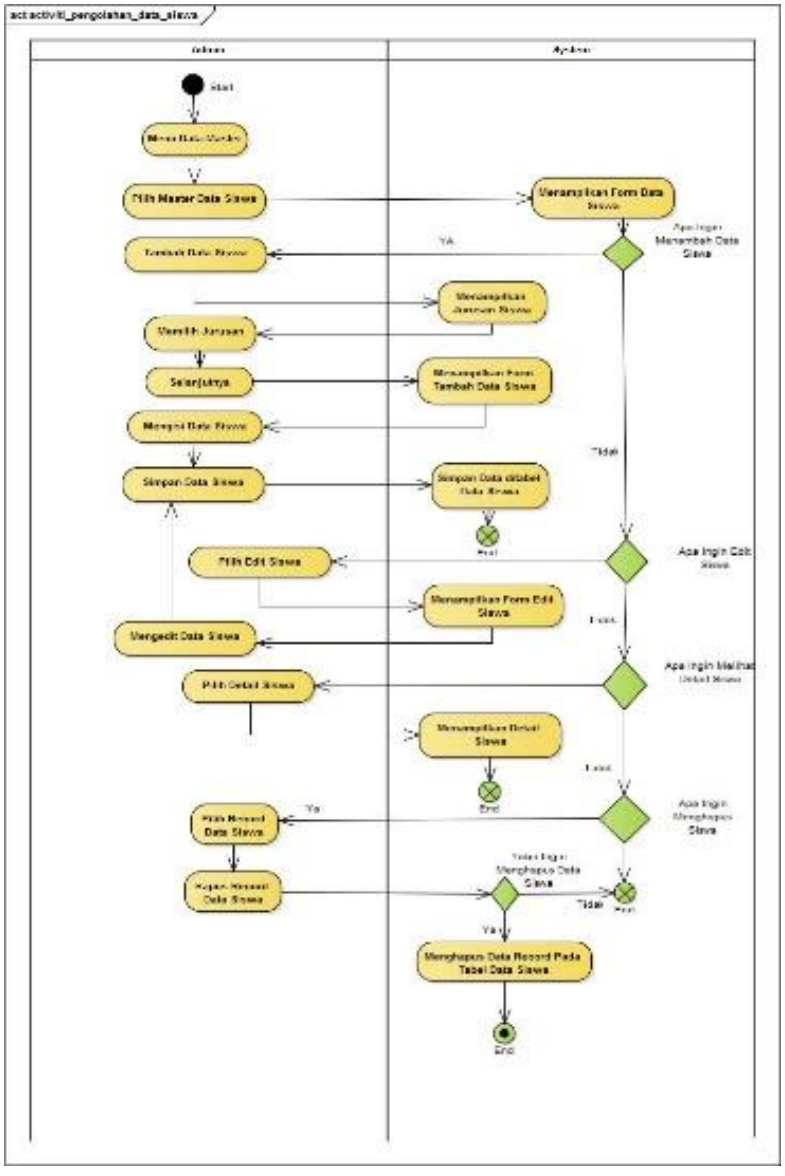

Gambar 2. Activity Data Siswa

DOI: $10.52362 /$ jisicom.v5i1.452

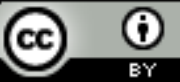

Ciptaan disebarluaskan di bawah Lisensi Creative Commons Atribusi 4.0 Internasional. 
e-ISSN : 2597-3673 (Online), p-ISSN : 2579-5201 (Printed)

Vol.5 No.1, Juni 2021

Journal of Information System, Informatics and Computing

Website/URL: http://journal.stmikjayakarta.ac.id/index.php/jisicom

Email: jisicom@stmikjayakarta.ac.id , jisicom2017@gmail.com

3. Data Mata Pelajaran

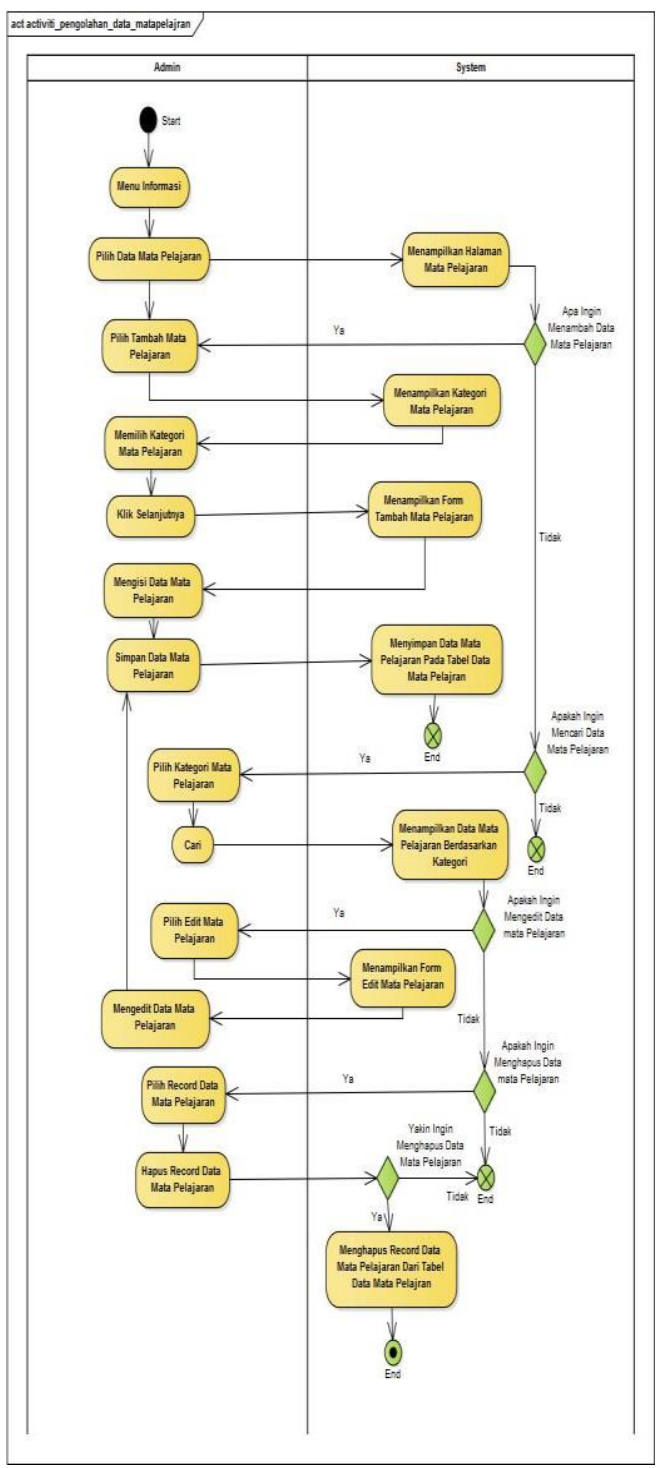

4. Data Hasil Nilai Siswa

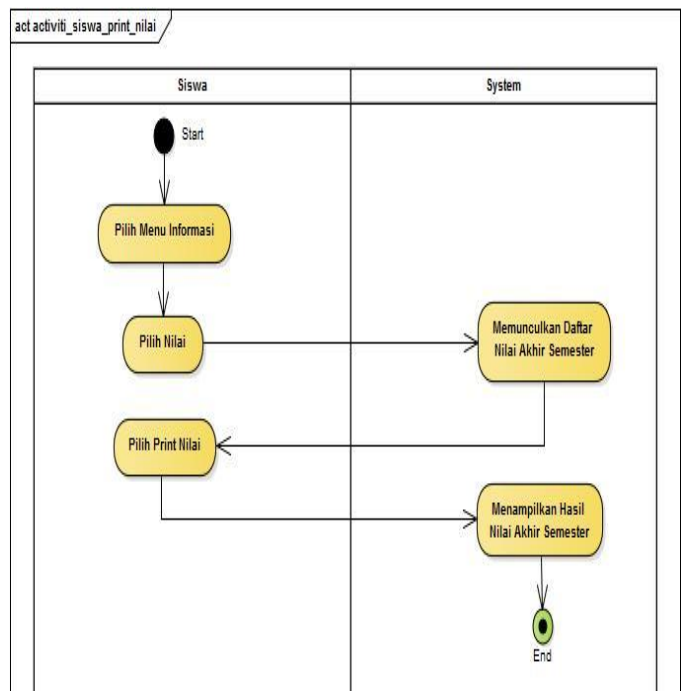

5. Class Table Relation

Gambar 3 Activity Data Mata Pelajaran

DOI: $10.52362 /$ jisicom.v5i1.452

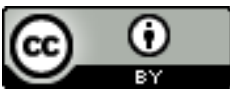

Ciptaan disebarluaskan di bawah Lisensi Creative Commons Atribusi 4.0 Internasional. 
e-ISSN : 2597-3673 (Online), p-ISSN : 2579-5201 (Printed)

Vol.5 No.1, Juni 2021

Journal of Information System, Informatics and Computing

Website/URL: http://journal.stmikjayakarta.ac.id/index.php/jisicom

Email: jisicom@stmikjayakarta.ac.id, jisicom2017@gmail.com

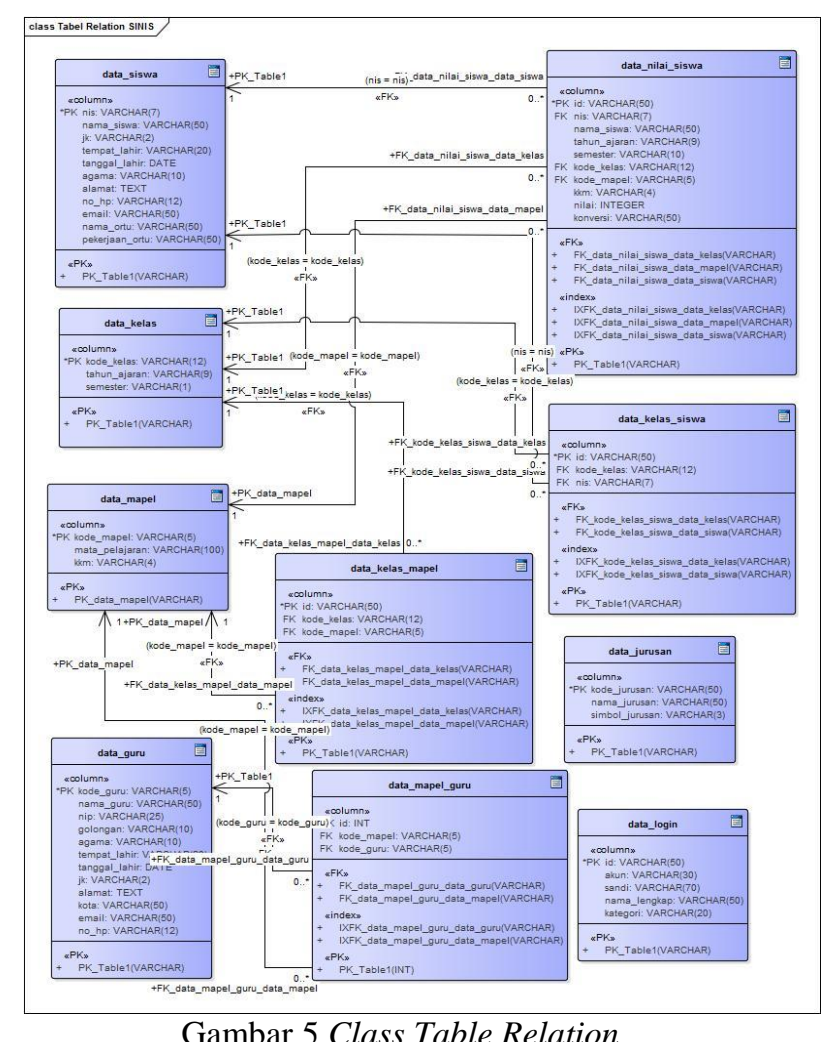

Gambar 5 Class Table Relation

\section{PEMBAHASA DAN HASIL}

Sistem Informasi ini yang dihasikan berbasis web online menggunakan aplikasi web browser dengan bahasa pemrograman PHP dan MySQL databasenya.

\subsection{Halaman Login}

Dalam login diharuskan mengisi username, password dan level, dalam level sendiri menentukan user apakah sebagai Admin atau Siswa.

\subsection{Dashboard}

Datsboard pada Sistem Informasi Penilain Siswa SMK Maarif Kabupaten Tegal terdapat beberapa menu yaitu Dashboard, data master, informasi dan tampilan ini adalah tampilan yang akan muncul ketika Admin telah berhasil login.

DOI: $10.52362 /$ jisicom.v5i1.452

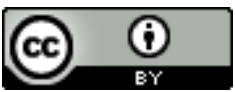

Ciptaan disebarluaskan di bawah Lisensi Creative Commons Atribusi 4.0 Internasional. 
e-ISSN : 2597-3673 (Online), p-ISSN : 2579-5201 (Printed)

Vol.5 No.1, Juni 2021

Journal of Information System, Informatics and Computing

Website/URL: http://journal.stmikjayakarta.ac.id/index.php/iisicom

Email: jisicom@stmikjayakarta.ac.id, jisicom2017@gmail.com

SINIS Dashiboard Mater Data = Informasi -
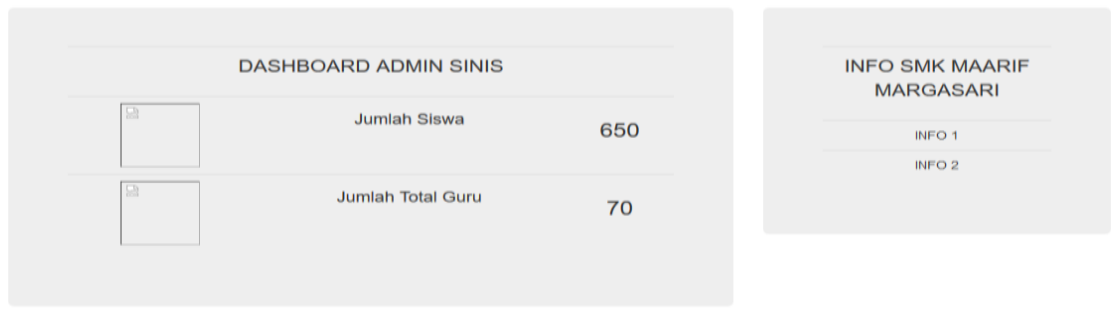

Gambar 6 Form Dashboard

3.3. Sub Menu Data Guru

Pada Sub Menu Guru, Admin dapat menambah, mengedit dan menghapus data, pencarian data guru berdasarkan nama dan juga dapat melihat detail setiap guru.

SINIS Dashboaid Maler Data - Inflominasi - Selamat Datang. Administralor -

3.4. Sub Menu Data Siswa

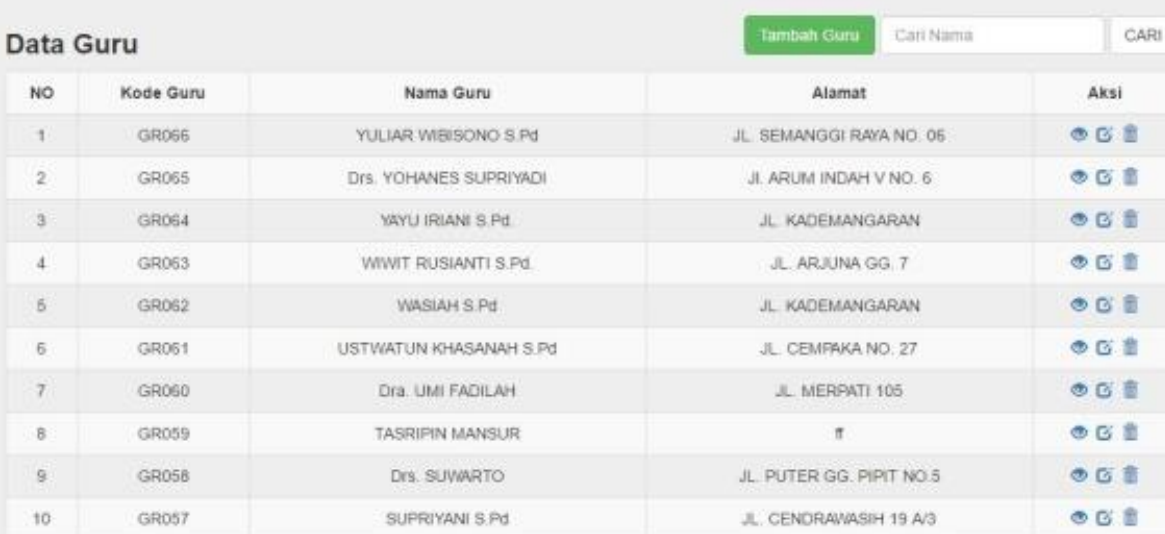

\section{Gambar 7 Form Sub Menu Data Guru}

Pada Sub Menu data guru, Admin dapat menambah, mengedit dan menghapus data, pencarian data siswa berdasarkan nama dan nim dan juga dapat melihat detail setiap siswa.

DOI: $10.52362 /$ jisicom.v5i1.452

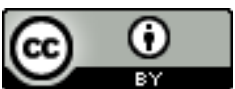

Ciptaan disebarluaskan di bawah Lisensi Creative Commons Atribusi 4.0 Internasional. 
e-ISSN : 2597-3673 (Online), p-ISSN : 2579-5201 (Printed)

Journal of Information System, Informatics and Computing

Website/URL: http://journal.stmikjayakarta.ac.id/index.php/jisicom

Email: jisicom@stmikjayakarta.ac.id, jisicom2017@gmail.com
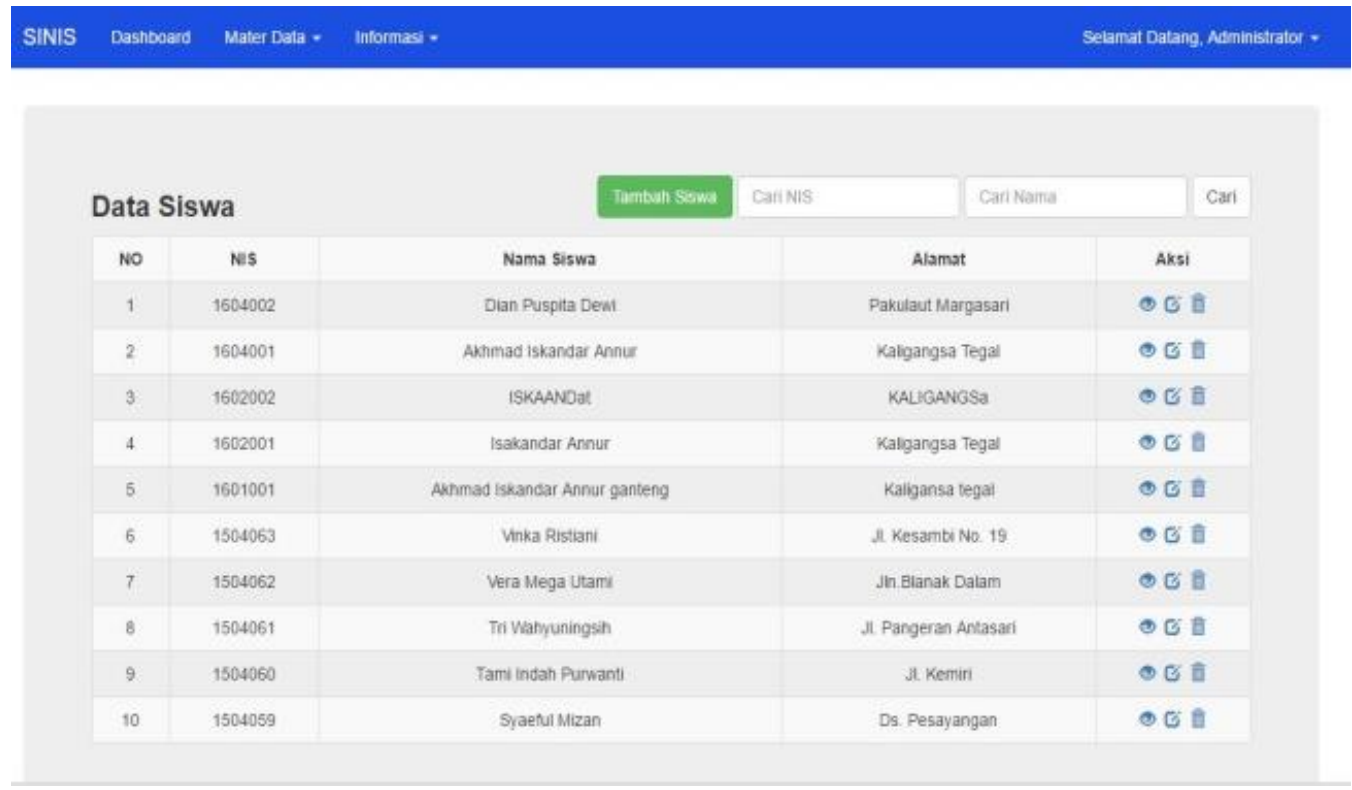

Gambar 8 Form Sub Menu Data Siswa

\subsection{Sub Menu Data Kelas}

Pada Sub Menu data kelas, Admin dapat menambah, melihat detail kelas, dan hapus kelas serta dapat menambah matapelajaran dan menambah siswa ke dalam kelas tersebut.
SINIS Dashboard Mater Data * Informasi *
Selamat Datang, Administrator •

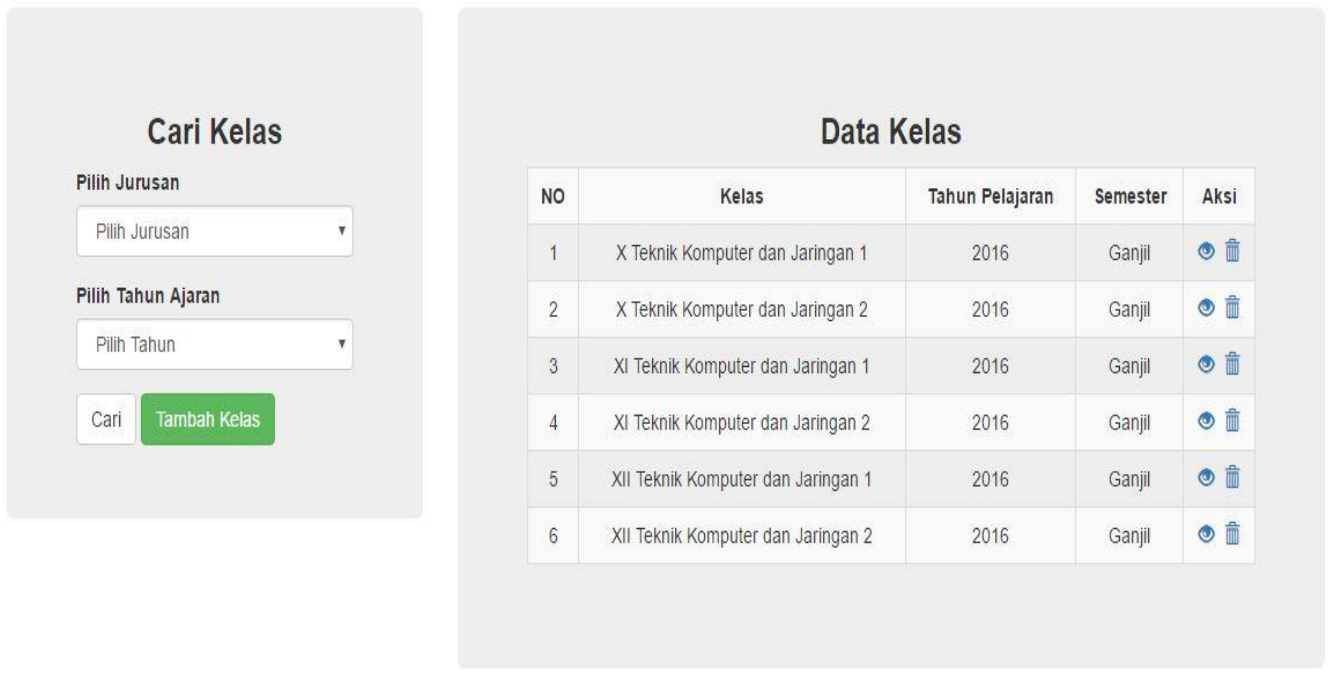

Gambar 9 Form Sub Menu Data Kelas

3.6. Sub Menu Data Nilai

Pada Sub Menu data nilia, Admin dapat mengedit nilai disetiap kelas yang akan dinilai.

DOI: $10.52362 /$ jisicom.v5i1.452

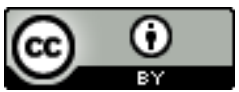

Ciptaan disebarluaskan di bawah Lisensi Creative Commons Atribusi 4.0 Internasional. 
e-ISSN : 2597-3673 (Online), p-ISSN : 2579-5201 (Printed)

Vol.5 No.1, Juni 2021

Journal of Information System, Informatics and Computing

Website/URL: http://journal.stmikjayakarta.ac.id/index.php/iisicom

Email: jisicom@stmikjayakarta.ac.id , jisicom2017@gmail.com

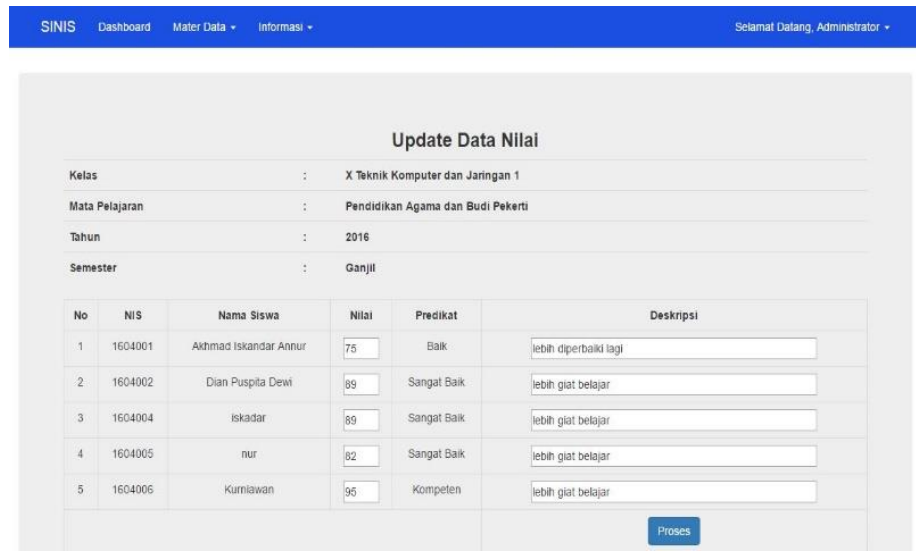

Gambar 10 Form Sub Menu Data Nilai

3.7. Sub Menu Hasil Nilai Siswa

Pada Sub Menu data hasil nilai, siswa login sistem dan memilih informasi hasil nilai setiap akhir semester.

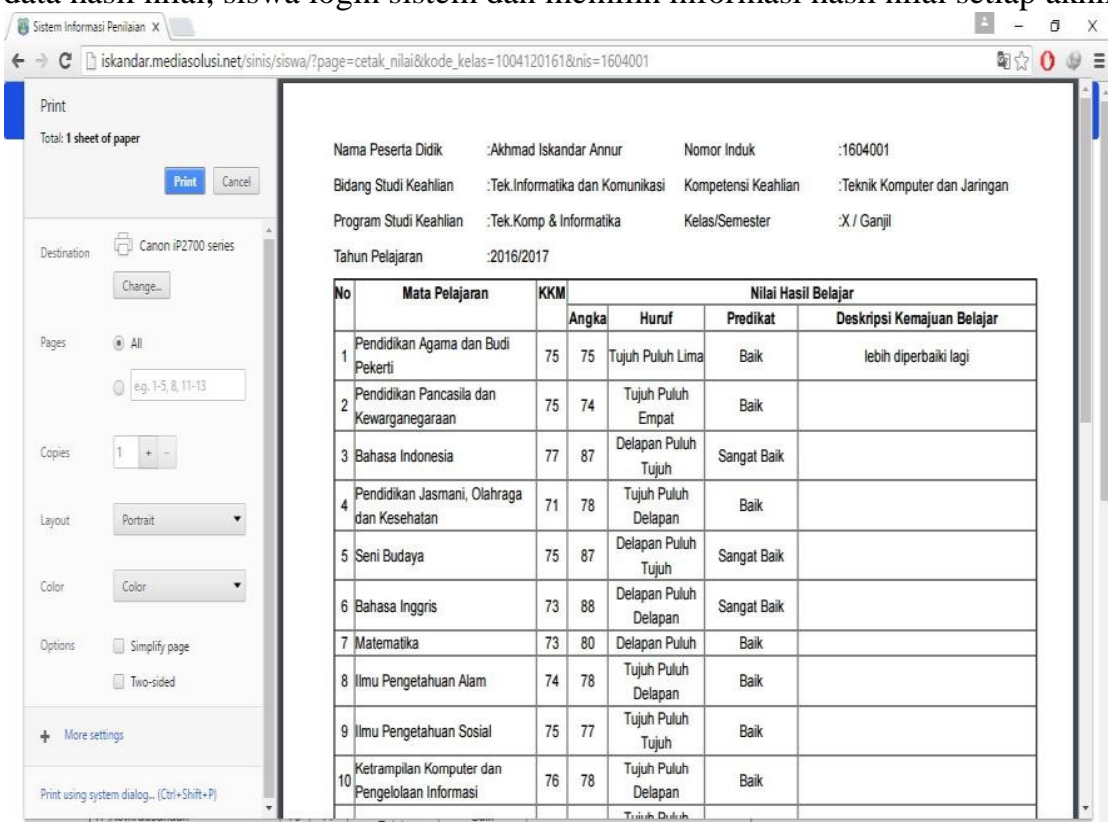

Gambar 11 Form Sub Menu Hasil Nilai

\section{KESIMPULAN}

Kesimpulan yang dapat diambil adalah dengan menggunakan bahasa pemograman PHP dan database mysql dapat digunakan untuk membangun sistem informasi penilaian, dimana didalamnya mencakup pengolahan data nilai, proses pencarian data, proses print hasil nilai.

Pada proses perancangan ini menggunakan UML dimana diagram yang digunakan hanya use case diagram, sequence diagram, activity diagram dan class Table Relation.

DOI: $10.52362 /$ jisicom.v5i1.452

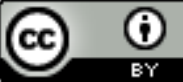

Ciptaan disebarluaskan di bawah Lisensi Creative Commons Atribusi 4.0 Internasional. 
e-ISSN : 2597-3673 (Online), p-ISSN : 2579-5201 (Printed)

Vol.5 No.1, Juni 2021

Journal of Information System, Informatics and Computing

Website/URL: http://journal.stmikjayakarta.ac.id/index.php/jisicom

Email: jisicom@stmikjayakarta.ac.id , jisicom2017@gmail.com

\section{REFERENSI}

[1] Elpraditya, H. 2012. Analisis dan Perancangan Aplikasi Pengolahan Nilai Siswa SMP Joannes Bosco Yogyakarta Berbasis Java. STMIK Amikom Yogyakarta : Naskah Publikasi.

[2] LouisO.Kattsoff. Pengantar Filsafat, Terjemahan oleh Soejono Soemargo. Yogyakarta:Tiara Waca Yogya.1984

[3] Kurniawan, Rulianto.2010.PHP dan MySQL Untuk Orang Awam. Palembang:Maxikom.

[4] Saputra, Agus.2011.Trik Dan Solusi Pemgraman PHP. Elex Media Komputindo.

[5] Nugroho Adi, 2004. Konsep Pengembangan Sistem Basis Data. Informatika Bandung

[6] Nugroho, Bunafit. Membangun Sistem Informasi Berbasis WEB dengan PHP dan MySQL. Yogyakarta:Gava Media.20

[7] Sampurna.Internet dan Aplikasinya.Jakarta: Elex Media Komputindo.1996

[8] Sidik, Betha.2014.Pemrograman Web PHP Revisi Kedua. Bandung : Informatika.

[9] Sutarman.Pengantar Teknologi Informasi. Yogyakarta:Bumi Aksara. 2009

[10] Wardani, Susi. 2013." Sistem Informasi Pengolahan Data Nilai Siswa Berbasis Web Pada Sekolah Menengah Kejuruan (SMK) PGRI 1 Pacitan”. Indonesian Journal on Networking and Security (IJNS).2(4), 12-19

[11] Smileshoot.2011.Definisi Disertasi, Tesis, Skipsi, Prosing dan Jurnal.[Online]. Tersedia: https://smileshoot.wordpress.com/2011/06/30/defenisi-disertasitesis-skripsi-prosiding-dan-jurnal/ [28 Maret2015].

[12] Getting Started With Bootstrap.[Online] Tersedia : [29 Maret 2015].

[13] Pusat Makalah. 2012. Makalah Web Browser. Tersedia : http://www.pusatmakalah.com/2014/12/makalah-webbrowser.html [16 Desember 2014].

[14] Unified Modelling Languagre (UML).[Online] Tersedia : http://library.binus.ac.id/eColls/eThesisdoc/Bab2HTML/2013101063IFBab2001/page32.html [25 Maret 2016].

DOI: $10.52362 /$ jisicom.v5i1.452

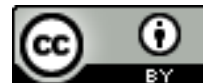

Ciptaan disebarluaskan di bawah Lisensi Creative Commons Atribusi 4.0 Internasional. 